\title{
BMJ open Influence of the 2009 financial crisis on detection of advanced pulmonary tuberculosis in Osaka city, Japan: a cross-sectional study
}

\author{
Katsura Danno, ${ }^{1,2}$ Jun Komukai, ${ }^{1}$ Hideki Yoshida, ${ }^{1}$ Kenji Matsumoto, ${ }^{1}$ \\ Shinichi Koda, ${ }^{1}$ Kazuhiko Terakawa, ${ }^{1}$ Hiroyasu $\mathrm{Iso}^{2}$
}

To cite: Danno K, Komukai J, Yoshida $\mathrm{H}$, et al. Influence of the 2009 financial crisis on detection of advanced pulmonary tuberculosis in Osaka city, Japan: a crosssectional study. BMJ Open 2013;3:e001489.

doi:10.1136/bmjopen-2012001489

- Prepublication history for this paper are available online. To view these files please visit the journal online (http://dx.doi.org/10.1136/ bmjopen-2012-001489).

Received 25 May 2012 Revised 24 January 2013 Accepted 28 January 2013

This final article is available for use under the terms of the Creative Commons Attribution Non-Commercial 2.0 Licence; see http://bmjopen.bmj.com

${ }^{1}$ Department of Infectious Diseases, Osaka City Public Health Office, Osaka City, Japan

${ }^{2}$ Public Health, Department of Social and Environmental Medicine, Osaka University Graduate School of Medicine, Suita City, Japan

Correspondence to Dr Hiroyasu Iso; iso@pbhel.med.osaka-u.ac.jp

\section{ABSTRACT}

Objective: To investigate the association between the economic recession and the detection of advanced cases of pulmonary tuberculosis in Osaka city from 2007 to 2009.

Design: A repeated cross-sectional study.

Setting: Osaka city has been the highest tuberculosis burden area in Japan. After the previous global financial crisis, the unemployment rate in Osaka prefecture has deteriorated from $5.3 \%$ in 2008 to $6.6 \%$ in 2009.

Participants: During the study period, 3406 pulmonary tuberculosis cases were enrolled: 2530 males and 876 females; 1546 elderly cases (65 years and above) and 1860 young cases (under 65 years); 417 homeless cases and 2989 nonhomeless cases.

Outcome measures: Patients' information included the sex, age, registry, health insurances, places of detection, sputum smear test results, patients' delay, doctors' delay and the grade of chest $x$-ray findings. They were statistically analysed between 2007 and 2008, two years before and just before the financial crisis, and between 2008 and 2009, just before and after the financial crisis.

Results: The total numbers of pulmonary tuberculosis cases were 1172 in 2007, 1083 in 2008 and 1151 in 2009. In health examinations for nonhomeless people, higher number of cases in 2009 were sputum smear positive, had respiratory symptoms and showed advanced disease in chest x-rays than those in 2008, with a longer patients' delay. On the contrary, in health examination for homeless people, fewer cases of advanced pulmonary tuberculosis were found in 2009 than in 2008, with a shorter patients' delay. In clinical examinations, there was no trend towards a difference between nonhomeless and homeless people.

Conclusions: Although homeless people might be protected by public assistance, tuberculosis prevention and control need to be reinforced for the non-homeless population after the financial crisis.

\section{ARTICLE SUMMARY}

Article focus

- Research question: How did the global financial crisis of 2007-2008 affect pulmonary tuberculosis in Japan?

- Hypothesis (1): The homeless patients, the vulnerable group, might develop more serious diseases because of worse impoverishment caused by the global financial crisis of 2007-2008.

- Hypothesis (2): The non-homeless patients might not be influenced by the global financial crisis of 2007-2008 because they have the national health insurance coverage.

Key messages

- The homeless patients, the vulnerable group, were detected with less-advanced pulmonary tuberculosis stages soon after the global financial crisis of 2007-2008.

- The non-homeless patients were detected with more advanced tuberculosis stages soon after the global financial crisis of 2007-2008.

- The findings might be explained by the Japanese national social insurance and welfare systems. Changes should be made to protect the nonhomeless in economic restraint.

Strengths and limitations of this study

- The database we used was reliable enough for analysis, which was collected by precise measurement.

- We used the quantitative data which allowed sophisticated statistical analysis.

- We could assume that all people living in Japan had the health insurance coverage and had been provided health service under its scheme. Hence we could imply our results straightforwardly to the Japanese national health insurance and welfare system.

- We had no information on the changes in patients' health-seeking behaviours before and after the economic recession.

- The period for the study was relatively short. Therefore it might have caused a chance of finding. 


\section{INTRODUCTION}

The Japanese economy suffered recently when the world financial crisis began in August 2007, and after the bankruptcy of Lehman Brothers in September 2008. Numerous temporary workers were laid off, and the national unemployment rate rose from $3.9 \%$ in 2007 to $5.1 \%$ in 2009 after having improved from $5.3 \%$ in $2003 .{ }^{1}$ The unemployment rate in Osaka prefecture, which consistently had a higher unemployment rate than the national average, rose from $5.3 \%$ in 2007 to $6.6 \%$ in 2009 after improving from $7.6 \%$ in 2003.

The global financial crisis threatened global health, particularly because of diseases associated with poverty, such as tuberculosis. ${ }^{2}$ When a financial crisis occurred in 1998 after the dissolution of the Soviet Union in 1991, there was a resurgence of tuberculosis in $1999 .{ }^{3}{ }^{4}$ The case detection rate and the cure rate fell, and the frequency of severe cases and the fatality rate increased. A deterioration of tuberculosis was also observed during 1995-1997 in Tajikistan, which is one of the poorest former Soviet republics. ${ }^{5}$ The resurgence of tuberculosis cases and deaths was also observed in Central and Eastern European countries after the Soviet Union collapsed, and it continued even after 2000. ${ }^{6}$ With regard to the world financial crisis beginning in 2007, an increase in tuberculosis incident cases in London was observed among immigrants from Eastern Europe. ${ }^{7}$ The deterioration of the tuberculosis status in these countries was relevant, because the reduction in funds led to insufficient tuberculosis control services, such as shortages in the supply of drugs, chest x-ray material, laboratory supplies and tuberculin skin tests. ${ }^{5}$ In addition, the financial upheaval led to less-effective system of patient diagnosis and management. ${ }^{4}$ To make matters worse, the economic decline caused unemployment and an increase in the homeless population, both of which are risk factors for tuberculosis. ${ }^{8-11}$

It has been reported that the financial crisis provided an opportunity to reconsider the established practices and policies to improve health system performance. ${ }^{2}$ Tuberculosis control is a useful indication to explore the impact of the global financial crisis on health. ${ }^{12}$ Reinforcing the social safety nets in terms of healthcare, employment security, housing and the food supply would help reduce the adverse effects of economical upheaval and would promote health. ${ }^{13}$

In contrast to the aforementioned finding, the tuberculosis incidence rate (per 100000 population) in Japan improved after the world financial crisis: from 19.8 in 2007 to 19.4 in 2008 and to 19.0 in 2009. The trend was also seen in Osaka city: from 52.9 in 2007 to 50.6 in 2008 and to 49.6 in $2009 .{ }^{14}$ These statistics suggested that the economic recession did not deteriorate the tuberculosis control services in Japan, but actually improved it, which was inconsistent with what was previously reported in European countries. However, we hypothesised that there would be unpredictable shifts if the patients' variables were examined in detail, since there has not been a detailed study reported in Japan. Therefore, the aim of this study was to elucidate the associations between the latest economic recession and the demographics of the pulmonary tuberculosis patients, how they were detected, the severity of pulmonary tuberculosis, the length of time between when patients noted symptoms and visited the health clinic and the length of time between the visit and the diagnosis.

\section{METHODS}

\section{Study setting}

Osaka city, with a 2009 census population of $2661700^{15}$ is the capital city of Osaka prefecture, the second biggest in Japan following Tokyo. Osaka city has had the worst tuberculosis prevalence in Japan since 1997, at 37.7 per 100000 people in $2010 .^{16}$ This is probably because Osaka city has the largest population of homeless on the street in all of Japan. The 2009 census revealed that $3724(23.6 \%)$ of 15759 homeless people in Japan resided in Osaka city. ${ }^{17}$ This may be because Osaka city had the biggest residential area for casual labourers. Most of them were temporary construction workers without residential registration. They were vulnerable to losing their jobs owing to an economic recession or when diseased, and are likely to start living on the street when they are unable to pay for transient hotels. In this research study, the 'homeless' were defined as people who did not have residential registration at the time when they were diagnosed with pulmonary tuberculosis, which included both construction labourers without residential registration and homeless people living on the street.

\section{Data collection and statistical analysis}

Japanese physicians are legally required to register all tuberculosis patients immediately after the diagnosis. ${ }^{18}$ The information included in the medical records on every patient is transferred to the public health centre, where the it is compiled in the database of the National Epidemiological Surveillance of Infectious Disease (NESID), run by the Japanese Anti-Tuberculosis Association (JATA). The data analysed in this study were obtained from this surveillance system. The database includes the sex, age, address, health insurances, place of detection, sputum smear test results, patients' delay, doctors' delay and the grade of chest x-ray findings. We defined the patients' delay as the lag time between the first date of sickness and the first visit to a tuberculosis examination centre or healthcare facility. We defined the doctors' delay as the lag time between the first date of the patient's visit to the healthcare facility and the date when the diagnosis was made. These variables were collected for the period before and after the world financial crisis, that is, from 2007 to 2009. Advanced pulmonary tuberculosis was evaluated based on the symptoms, chest $\mathrm{x}$-ray findings and sputum smear tests. The severity of chest $\mathrm{x}$-rays was classified from grades 1 to 3 by the Japanese Society for Tuberculosis Criteria. ${ }^{19}$ Grade 1 is defined as 
minimal lung disease, in which the dimension of the infiltrates is smaller than the dimension of a lung portion: the portion enclosed from a horizontal line through a second rib up to a lung apex. Grade 3 is an advanced lung disease, in which the dimension of infiltrates is larger than the dimension of one lung. Grade 2 is moderately advanced disease, in which the total infiltrates is between grades 1 and 3. 'Unknown data' were present when the patients were unable to answer the interview questions properly, and/or when the interviewers collected inaccurate information.

The statistical analysis was performed using Microsoft Office Excel 2007. The proportions of the population of interest were compared between 2007 and 2008, and between 2008 and 2009, using $\chi^{2}$ tests. The average values of interest were compared between 2007 and 2008, and between 2008 and 2009, using Student t test.

Ethical approval for this study was obtained from the Osaka University Research Ethics Committee (No.10089). In addition, this research was approved by the health authorities of the Osaka City Government.

\section{Opportunities of pulmonary tuberculosis detection}

Tuberculosis patients were classified based on how they were diagnosed: health examinations, clinical examinations and contact investigations. Health examinations, where tuberculosis patients are actively found, are carried out periodically, generally once or twice a year. ${ }^{18}$ They are conducted for citizens by government agencies, for employees by company employers, for elderly people by nursing home directors, for inmates by prison directors and for the homeless by refugee centre directors. All of these health examinations are free of charge in Osaka city. On the other hand clinical examinations, where tuberculosis patients are found passively, are performed for patients who spontaneously visited hospitals or clinics. For clinical examinations, patients are required to pay copayments. Contact investigations are targeted on people highly exposed to contagious pulmonary tuberculosis patients. Patients with any tuberculosis symptoms were interviewed, and all of them submitted to chest $\mathrm{x}$-rays. Those with chest $\mathrm{x}$-rays suggestive of tuberculosis underwent further examinations, including sputum smear tests.

\section{RESULTS}

\section{Characteristics of the incident pulmonary tuberculosis cases}

The study population consisted of 1172, 1083 and 1151 cases of pulmonary tuberculosis in 2007, 2008 and 2009, respectively (table 1 ). The proportion of homeless pulmonary tuberculosis patients did not change between 2007 and 2008. However it decreased significantly, from 143 cases $(13.2 \%)$ in 2008 to 118 cases $(10.3 \%)$ in 2009 ( $p$ value $=0.03$ ). The size of the homeless population in Osaka city fluctuated during the study period, with 4069 in 2007, 3647 in 2008 and 3724 in $2009 .{ }^{17}$ The number of non-homeless pulmonary tuberculosis cases did not change between 2007 and 2009. The population of nonhomeless people in Osaka city increased slightly during the study period, from 2643805 in 2007, to 2652099 in 2008 and to 2661700 in $2009 .^{15}$ The number of health examination cases did not change between 2007

Table 1 Characteristics of incident pulmonary tuberculosis cases in 2007, 2008 and 2009

\begin{tabular}{|c|c|c|c|c|c|c|c|c|}
\hline \multirow[b]{2}{*}{ Variables } & \multicolumn{2}{|l|}{2007} & \multicolumn{2}{|l|}{2008} & \multirow{2}{*}{$\begin{array}{l}\text { p Value } \\
\text { (2007 vs 2008) }\end{array}$} & \multicolumn{2}{|l|}{2009} & \multirow{2}{*}{$\begin{array}{l}\text { p Value } \\
\text { (2008 vs 2009) }\end{array}$} \\
\hline & $\mathbf{n}$ & Percentage & $\mathbf{n}$ & Percentage & & $\mathbf{n}$ & Percentage & \\
\hline Total number of subjects & 1172 & 100.0 & 1083 & 100.0 & & 1151 & 100.0 & \\
\hline \multicolumn{9}{|c|}{ Sex } \\
\hline Male & 890 & 75.9 & 814 & 75.2 & \multirow[t]{2}{*}{0.67} & 826 & 71.8 & \multirow[t]{2}{*}{0.07} \\
\hline Female & 282 & 24.1 & 269 & 24.8 & & 325 & 28.2 & \\
\hline \multicolumn{9}{|l|}{ Age } \\
\hline$<65$ & 642 & 54.8 & 595 & 54.9 & \multirow[t]{2}{*}{0.94} & 623 & 54.1 & \multirow[t]{2}{*}{0.70} \\
\hline$\geq 65$ & 530 & 45.2 & 488 & 45.1 & & 528 & 45.9 & \\
\hline \multicolumn{9}{|l|}{ Registry } \\
\hline Homeless & 156 & 13.3 & 143 & 13.2 & \multirow[t]{2}{*}{0.94} & 118 & 10.3 & \multirow[t]{2}{*}{0.03} \\
\hline Non-homeless & 1016 & 86.7 & 940 & 86.8 & & 1033 & 89.7 & \\
\hline \multicolumn{9}{|l|}{ Job } \\
\hline Unemployed & 851 & 72.6 & 757 & 69.9 & \multirow[t]{2}{*}{0.15} & 812 & 70.5 & \multirow[t]{2}{*}{0.74} \\
\hline Employed & 321 & 27.4 & 326 & 30.1 & & 339 & 29.5 & \\
\hline \multicolumn{9}{|l|}{ Health insurance } \\
\hline Non-subscriber & 385 & 32.8 & 362 & 33.4 & \multirow[t]{2}{*}{0.77} & 373 & 32.4 & \multirow[t]{2}{*}{0.61} \\
\hline Subscriber & 787 & 67.2 & 721 & 66.6 & & 778 & 67.6 & \\
\hline \multicolumn{9}{|l|}{ Type of examination } \\
\hline Health examination & 123 & 10.5 & 108 & 10.0 & \multirow[t]{3}{*}{0.69} & 168 & 14.6 & \multirow[t]{3}{*}{0.002} \\
\hline Clinical examination & 950 & 81.1 & 882 & 81.4 & & 920 & 79.9 & \\
\hline Others & 99 & 8.4 & 93 & 8.6 & & 63 & 5.5 & \\
\hline
\end{tabular}


Table 2 Trends in the number and the proportion of incident pulmonary tuberculosis cases among homeless and non-homeless by type of examination

\begin{tabular}{|c|c|c|c|c|c|c|c|c|}
\hline \multirow[t]{2}{*}{ Variables } & \multicolumn{2}{|l|}{2007} & \multicolumn{2}{|c|}{2008} & \multirow{2}{*}{$\begin{array}{l}\text { p Value } \\
\text { (2007 vs 2008) }\end{array}$} & \multicolumn{2}{|l|}{2009} & \multirow[b]{2}{*}{$\begin{array}{l}\text { p Value } \\
\text { (2008 vs 2009) }\end{array}$} \\
\hline & $\mathbf{n}$ & $\%$ & $\mathbf{n}$ & $\%$ & & $\mathbf{n}$ & Percentage & \\
\hline Homeless, total & 156 & 100.0 & 143 & 100.0 & & 118 & 100.0 & \\
\hline Health examination & 28 & 17.9 & 25 & 17.5 & 0.85 & 51 & 43.2 & $<0.001$ \\
\hline Clinical examination & 109 & 69.9 & 103 & 72.0 & & 62 & 52.5 & \\
\hline Others & 19 & 12.2 & 15 & 10.5 & & 5 & 4.2 & \\
\hline Non-homeless, total & 1016 & 100.0 & 940 & 100.0 & & 1033 & 100.0 & \\
\hline Health examination & 95 & 9.4 & 83 & 8.8 & 0.72 & 117 & 11.3 & 0.10 \\
\hline Clinical examination & 841 & 82.8 & 779 & 82.9 & & 858 & 83.1 & \\
\hline Others & 90 & 8.9 & 78 & 8.3 & & 58 & 5.6 & \\
\hline
\end{tabular}

and 2008, but increased remarkably between 2008 and 2009 , from 108 cases $(10.0 \%)$ to 168 cases $(14.6 \%)$ ( $\mathrm{p}$ value $=0.002)$. The number of clinical examination cases did not change between 2007 and 2009. The others were the cases detected in contact investigations. The number of cases in female population increased between 2008 and 2009. Both the male and female populations increased in Osaka city, with 1287626 males in 2007, 1291975 in 2008 and 1298011 in 2009 and 1356179 females in 2007, 1360124 in 2008 and 1363689 in $2009 .^{15}$

Trends in the incidence of pulmonary tuberculosis cases in homeless and non-homeless people based on the type of examination

The total number of homeless cases decreased between 2007 and 2009 (table 2). However, the cases in health examination increased and that in clinical examination decreased significantly between 2008 and 2009, from 25 $(17.5 \%)$ to $51(43.2 \%)$, and from $103(72.0 \%)$ to 62 $(52.5 \%)$, respectively, ( $\mathrm{p}$ value $<0.001)$. The others were the cases detected in contact investigations. The total number of non-homeless cases did not change substantially between 2007 and 2009. The cases in health examination increased, although not significantly, and those in clinical examination did not change substantially between 2008 and 2009, from $83(8.8 \%)$ to $117(11.3 \%)$, and from $779(82.9 \%)$ to $858(83.1 \%)$, respectively, ( $\mathrm{p}$ value $=0.10)$.

Trends in the incidence of advanced pulmonary tuberculosis cases in homeless and non-homeless patients based on the type of examination

Among non-homeless cases, sputum smear positivity, the presence of respiratory symptoms and the presence of advanced chest x-ray findings in the health examination did not show any particular trend between 2007 and 2008 (table $3)$. However all of them increased sharply between 2008 and 2009 ( $p$ value $=0.05,0.26$ and 0.005 , respectively). These variables in the clinical examinations significantly, but inconsistently, changed between 2007 and 2008 ( $p$ value $=0.002$, $<0.001$ and 0.001 , respectively). They did not show any common trends between 2007 and 2009. On the other hand, among homeless cases, these variables in the health examinations sharply increased between 2007 and 2008 ( $p$ value $=0.002,0.03$ and 0.07 , respectively). However, they decreased steeply between 2008 and 2009 ( $p$ value $=0.007$, 0.003 and 0.47 , respectively). These variables in the clinical examination did not change between 2007 and 2009.

Table 4 shows the average patients' and doctors' delays. The average patients' delay among non-homeless cases detected by health examination increased between 2008 and 2009, from 12.8 days to 32.0 days $(\mathrm{p}=0.13)$. This finding corresponded to the increasing trend in advanced cases detection in this group (table 3 ). On the other hand, the average patients' delay among homeless cases detected by health examination increased significantly between 2007 and 2008, from 20.9 days to 107.5 days $(p$ value $=0.02$ ). It decreased, although not significantly, between 2008 and 2009, from 107.5 days to 76.0 days $(\mathrm{p}$ value $=0.49$ ). This tendency corresponded to the trend in advanced cases detection in this group. As for the average doctors' delay among non-homeless cases detected by clinical examination decreased significantly between 2007 and 2008, from 87.6 days to 22.3 days ( $p$ value $<0.01$ ). This finding corresponded to the increase in the presence of respiratory symptoms cases in this group. It was likely because the more severe the pulmonary tuberculosis was at presentation, the sooner the doctor could make a precise diagnosis.

\section{DISCUSSION}

In the present study, the non-homeless pulmonary tuberculosis cases were more likely to be found at advanced stages and with longer patients' delay by health examinations after the recession. In contrast, more homeless people were likely to receive health examinations, and be detected in earlier stages of pulmonary tuberculosis with a shorter patients' delay.

Our findings may be linked to Japanese health and welfare system. In Japan, co-payments are required when patients consult physicians under the Japanese health insurance system. The patients are required to pay 10 $30 \%$ of the total medical fee. ${ }^{20}$ When the global economy 
Table 3 Trends in the number and the proportion of sputum smear positive, presence of respiratory symptoms positive and advanced chest $\mathrm{x}$-rays among homeless and non-homeless by type of examination

\begin{tabular}{|c|c|c|c|c|c|c|c|c|}
\hline \multirow[b]{2}{*}{ Variables } & \multicolumn{2}{|c|}{2007} & \multicolumn{2}{|l|}{2008} & \multirow{2}{*}{$\begin{array}{l}\text { p Value } \\
\text { (2007 vs 2008) }\end{array}$} & \multicolumn{2}{|l|}{2009} & \multirow{2}{*}{$\begin{array}{l}\text { p Value } \\
\text { (2008 vs 2009) }\end{array}$} \\
\hline & $\mathbf{n}$ & $\%$ & $\mathbf{n}$ & $\%$ & & $\mathbf{n}$ & $\%$ & \\
\hline \multicolumn{9}{|l|}{ Homeless } \\
\hline Health examination, total & 28 & 100.0 & 25 & 100.0 & & 51 & 100.0 & \\
\hline Sputum smear test positive & 6 & 21.4 & 13 & 52.0 & 0.02 & 11 & 21.6 & 0.007 \\
\hline Respiratory symptoms positive & 17 & 60.7 & 22 & 88.0 & 0.02 & 27 & 52.9 & 0.003 \\
\hline Chest $x$-ray grades 2 and 3 & 11 & 39.3 & 16 & 64.0 & 0.07 & 22 & 43.1 & 0.47 \\
\hline Clinical examination, total & 109 & 100.0 & 103 & 100.0 & & 62 & 100.0 & \\
\hline Sputum smear test positive & 64 & 58.7 & 58 & 56.3 & 0.72 & 42 & 67.7 & 0.15 \\
\hline Respiratory symptoms positive & 77 & 70.6 & 77 & 74.8 & 0.50 & 48 & 77.4 & 0.70 \\
\hline Chest $x$-ray grades 2 and 3 & 76 & 69.7 & 68 & 66.0 & 0.56 & 42 & 67.7 & 0.82 \\
\hline \multicolumn{9}{|l|}{ Non-homeless } \\
\hline Health examination, total & 95 & 100.0 & 83 & 100.0 & & 117 & 100.0 & \\
\hline Sputum smear test positive & 25 & 26.3 & 21 & 25.3 & 0.88 & 45 & 38.5 & 0.05 \\
\hline Respiratory symptoms positive & 27 & 28.4 & 31 & 37.3 & 0.20 & 53 & 45.3 & 0.26 \\
\hline Chest $\mathrm{x}$-ray grades 2 and 3 & 28 & 29.5 & 17 & 20.5 & 0.17 & 46 & 39.3 & 0.005 \\
\hline Clinical examination, total & 841 & 100.0 & 779 & 100.0 & & 858 & 100.0 & \\
\hline Sputum smear test positive & 546 & 64.9 & 446 & 57.3 & 0.002 & 525 & 61.2 & 0.11 \\
\hline Respiratory symptoms positive & 647 & 76.9 & 656 & 84.2 & $<0.001$ & 741 & 86.4 & 0.22 \\
\hline Chest $\mathrm{x}$-ray grades 2 and 3 & 627 & 74.6 & 523 & 67.1 & 0.001 & 615 & 71.7 & 0.05 \\
\hline
\end{tabular}

declined, non-homeless patients needed to cut down their cost of living. They were reluctant to consult clinics or hospitals because they did not want to pay the co-payments. Even though they were aware of their illness, some of them were likely to wait for the regular health examinations, which are held once or twice a year, because these are free in Osaka city. This resulted in delayed detection and more advanced stages at the time of diagnosis. This was clearly shown by the increase in advanced nonhomeless pulmonary tuberculosis cases in 2009, which was in consistence with the increased patients' delay. In Japan, the proportion of non-homeless households who could not afford premiums increased from $18.6 \%$ in 2007 to $20.6 \%$ in 2008 , and to $20.8 \%$ in $2009 .{ }^{21}$ Therefore, the non-homeless were likely to experience a decline in health during the recession because they needed to decrease their expenditures, which was reflected by the results of the present study.

On the other hand, pulmonary tuberculosis examinations were mandatory in Japan for homeless in refugee centres, prisoners, elderly people in nursing homes and frontline health and social care workers during this period. ${ }^{18}$ All of these people are examined when entering the facilities and annually thereafter. In the present financial crisis more and more casual labourers were laid off and became homeless, and more and more homeless were motivated to enter refugee centres. Most of them applied for public assistance, which covered all of their medical costs, in addition to their cost of living. However, they needed to stay in the refugee centres until they were offered welfare apartments. Therefore, they automatically received pulmonary tuberculosis

Table 4 Average \pm standard error of patients' delay in health and clinical examinations and of doctors' delay in clinical examinations among homeless and non-homeless

\begin{tabular}{|c|c|c|c|c|c|}
\hline & 2007 & 2008 & p Value (2007 vs 2008) & 2009 & p Value (2008 vs 2009) \\
\hline \multicolumn{6}{|l|}{ Patients' delay } \\
\hline \multicolumn{6}{|l|}{ Homeless } \\
\hline Health examination & $20.9 \pm 6.7$ & $107.5 \pm 36.0$ & 0.02 & $76.0 \pm 26.2$ & 0.49 \\
\hline Clinical examination & $59.9 \pm 17.4$ & $85.0 \pm 13.0$ & 0.26 & $65.3 \pm 11.0$ & 0.31 \\
\hline \multicolumn{6}{|l|}{ Non-homeless } \\
\hline Health examination & $21.1 \pm 5.6$ & $12.8 \pm 3.5$ & 0.23 & $32.0 \pm 10.3$ & 0.13 \\
\hline Clinical examination & $45.1 \pm 5.7$ & $42.6 \pm 4.6$ & 0.74 & $34.6 \pm 2.5$ & 0.11 \\
\hline \multicolumn{6}{|l|}{ Doctors' delay } \\
\hline Homeless & $7.6 \pm 1.7$ & $13.8 \pm 5.4$ & 0.26 & $8.2 \pm 2.8$ & 0.44 \\
\hline Non-homeless & $87.9 \pm 8.9$ & $22.3 \pm 2.1$ & $<0.001$ & $22.0 \pm 2.4$ & 0.93 \\
\hline
\end{tabular}


examinations when entering these facilities, resulting in the earlier detection of the disease.

With regard to public assistance, the target population used to be limited to elderly, disabled and mother-child households. However, in December 2008 the Japanese government expanded the target to unemployed people regardless of their ages, which included transient workers who had lost their jobs and incomes, and homeless people. This led to a steep increase and subsequent decline in the number of advanced homeless pulmonary tuberculosis cases detected in health examinations, which was consistent with the shorter patients' delay. On the other hand, the policy of tuberculosis case finding in Osaka city was neither strengthened nor weakened during the recession. Therefore, we do not know why the doctors' delay improved among non-homeless pulmonary tuberculosis cases in 2008.

Regarding the proportion of people receiving public assistance, Osaka city had the highest proportion among all other cities in Japan. ${ }^{22}$ The proportion increased steeply from $4.44 \%$ in 2008 to $4.99 \%$ in 2009 , which was well above the Japanese average increase from $1.25 \%$ in 2008 to $1.38 \%$ in 2009. Moreover, the number of people applying for public assistance increased nearly twofolds from April 2008 to April 2009 in Osaka city. ${ }^{23}$

These findings suggest that the tuberculosis prevention and control in Japan needed to have been reinforced for non-homeless after the financial crisis, while the homeless were well protected by the existing national health and welfare system. These findings were specific to Osaka city. However, the similar results would likely be observed in other cities which have similar demographics of homeless and construction workers.

Health examinations, that is active case detection, was reported to be efficient for detecting pulmonary tuberculosis patients with less-severe and less-contagious disease status. ${ }^{24}$ In contrast, clinical examination, that is passive case detection, frequently result in diagnostic delays. Therefore, these patients are likely to have more severe disease and be more contagious. In Japan, it is common to examine patients using chest $\mathrm{x}$-rays during pulmonary tuberculosis screenings before sputum smear tests. A study in Cape town confirmed that chest x-rays were a satisfactory screening tool for bacteriologically positive pulmonary tuberculosis, with a higher sensitivity than screening based on tuberculosis symptoms. ${ }^{25}$ Canadian surveys suggested that chest x-ray screenings for groups with a high prevalence of tuberculosis infection, such as among immigrants, were more cost-effective compared with tuberculin skin testing. ${ }^{26}{ }^{27}$ A South African study also suggested that chest $\mathrm{x}$-ray screening was a low-cost preventive intervention for immigrants from high prevalence countries. ${ }^{28}$

The number and the proportion of female pulmonary tuberculosis cases increased during the study period. This trend may be because of the higher proportion of elderly women than men. The proportion of elderly people (65 years and older) was $24-25 \%$ of women and was $19-20 \%$ of men between 2007 and $2009 .{ }^{15}$
Regarding the life expectancy, women live longer than men in Osaka city, with expected ages of 78.2 and 85.2 years, respectively. ${ }^{29}$ Elderly people were likely to develop reactivated tuberculosis because their weakened immune system owing to age.

One of the limitations of the present study was that there was no information on the changes in patients' health-seeking behaviours before and after the economic recession. The improving trend in detection of advanced pulmonary tuberculosis in homeless and deterioration trend in non-homeless patients may have been because of the national health and welfare system in Japan. In addition, the relatively short time period for the study might have caused a chance finding, that is, the differences may have been a natural fluctuation in tuberculosis detection.

\section{CONCLUSION}

This study suggests the impact of the recent economic recession might differ between homeless and nonhomeless people in Osaka city, Japan. In health examinations, a higher number of non-homeless patients with severe stages of pulmonary tuberculosis were found, while more homeless patients were diagnosed with earlier stages of the disease. These outcomes were explained in part by the Japanese legislation, national social insurance and welfare systems. The health services for tuberculosis detection and control could not be accessed as often by nonhomeless patients owing to economic reasons, while they were well provided for homeless patients by the present Japanese health and welfare system. Changes should therefore be made to protect the non-homeless working poor to prevent such issues in the future.

Acknowledgements We thank the staff of Health Support Osaka (HESO), NPO, for interviewing the homeless patients during health examinations. The authors appreciate the outreach team and logisticians of the Osaka Public Health Office, and Professor Toshio Takatorige, Faculty of Safety Science, Kansai University, for their support.

Contributors KD was the lead writer. JK was a colleague and worked with $\mathrm{KD}$ on collecting and validating the data. KM was a senior supervisor and responsible for data analysis and making tables. HY was a junior supervisor and responsible for conducting the survey. KT was the director and SK was the vice-director of the Osaka City Public Health Office, and both were the most responsible for publishing the data. HI was the professor at Osaka University Graduate School of Medicine and made the final decision of publishing. All authors were involved in conceiving the issue for investigation, designing the study, interpreting the data and critically revising the drafts of the manuscript until they reached the consensus for the final edition.

Funding This research received no specific grant from any funding agency in the public, commercial or not-for-profit sectors.

Competing interests None.

Ethics approval Osaka University Research Ethics Committee.

Provenance and peer review Not commissioned; externally peer reviewed.

Data sharing statement No additional data are available.

\section{REFERENCES}

1. Ministry of Health, Labor and Welfare. Annual Health, Labour and Welfare Report. 2009-2010:243-72. 
2. Maher D. Re-thinking global health sector efforts for HIV and tuberculosis epidemic control: promoting integration of programme activities within a strengthened health system. BMC Public Health 2010;10:394 .

3. Perelman Ml. Tuberculosis in Russia. Int $J$ Tuberc Lung Dis 2000;4:1097-103.

4. Shilova MV, Dye C. The resurgence of tuberculosis in Russia. Philos Trans R Soc Lond B Biol Sci 2001;356:1069-75.

5. Keshavjee S, Becerra MC. Disintegrating health services and resurgent tuberculosis in post-Soviet Tajikistan: an example of structural violence. JAMA 2000;283:1201.

6. Arinaminpathy $\mathrm{N}$, Dye $\mathrm{C}$. Health in financial crises: economic recession and tuberculosis in Central and Eastern Europe. J R Soc Interface 2010;7:1559-69.

7. Collinson S, Ward R. A nurse-led response to unmet needs of homeless migrants in inner London. Br J Nursing 2010;19:36-41.

8. Ladefoged K, Rendal T, Skifte T, et al. Risk factors for tuberculosis in Greenland: case-control study. Int J Tuberc Lung Dis 2011;15:44-9.

9. Coker R, McKee M, Atun R, et al. Risk factors for pulmonary tuberculosis in Russia: case-control study. BMJ 2006;332:85-7.

10. Couceiro L, Santana P, Nunes C. Pulmonary tuberculosis and risk factors in Portugal: a spatial analysis. Int J Tuberc Lung Dis 2011:15:1445-55.

11. Romaszko J, Buciński A, Wasiński R, et al. Incidence and risk factors for pulmonary tuberculosis among the poor in the northern region of Poland. Int $J$ Tuberc Lung Dis 2008;12:430-5.

12. Maher $\mathrm{D}$. Implications of the global financial crisis for the response to diseases of poverty within overall health sector development: the case of tuberculosis. Trop Med Int Health 2010;15:11-17.

13. Bezruchka S. The effect of economic recession on population health. CMAJ 2009;181:281-5.

14. http://www.jata.or.jp/rit/ekigaku/ (accessed 3 Aug 2012).

15. http://www.city.osaka.Ig.jp/keikakuchosei/page/0000015211.html (accessed 3 Aug 2012).
16. http://www.jata.or.jp/rit/ekigaku/toukei/pertinent material/ (accessed 22 Jul 2011).

17. http://www.mhlw.go.jp/bunya/seikatsuhogo/homeless10/ (accessed 3 Aug 2012).

18. Act on Prevention of Infectious Diseases and Medical Care for Patients Suffering Infectious Diseases, the third edition. 2008:70.

19. Tuberulosis Clinical Guidelines. The Japanese Society for Tuberculosis. 2010:14.

20. Social Insurance Agency. Overview of the social insurance systems, Social Insurance, 2007. http://www.sia.go.jp/e_old/ehi.html (accessed 22 Jul 2011)

21. http://www.mhlw.go.jp/topics/2010/02/tp0202-1.html (accessed 22 Jul 2011).

22. http://www.pref.osaka.jp/shakaiengo/syakaiengo/toukei.htm (accessed 22 Jul 2011).

23. http://www.city.osaka.lg.jp/kenkofukushi/page/0000086901.html (accessed 22 Jul 2011).

24. Ward HA, Marciniuk DD, Pahwa P, et al. Extent of pulmonary tuberculosis in patients diagnosed by active compared to passive case finding. Int J Tuberc Lung Dis 2004;8:593-7.

25. Den Boon S, White NW, Van Lill SW, et al. An evaluation of symptom and chest radiographic screening in tuberculosis prevalence surveys. Int J Tuberc Lung Dis 2006;10:876-82.

26. Menzies D. Screening immigrants to Canada for tuberculosis: chest radiography or tuberculin skin testing? CMAJ 2003;169:10.

27. Schwartzman K, Menzies D. Tuberculosis screening of immigrants to low-prevalence countries. A cost-effectiveness analysis. Am J Respir Crit Care Med 2000;161:780-9.

28. Den Boon S, Verver S, Lombard CJ, et al. Comparison of symptoms and treatment outcomes between actively and passively detected tuberculosis cases: the additional value of active case finding. Epidemiol Infect 2008;136:1342-9.

29. http://www.mhlw.go.jp/toukei/saikin/hw/life/tdfk05/02.html (accessed 3 Aug 2012). 